\title{
Keragaan 30 Hibrida Cabai (Capsicum annuum L.) Hasil Persilangan Cabai Besar dan Cabai Keriting
}

\section{Performance of 30 Chili Hybrid as Cross Combination of Big and Curly Chili (Capsicum annuum L.)}

\author{
Muhammad Ridha Alfarabi Istiqlal ${ }^{1,2}$, Muhamad Syukur ${ }^{2 *}$, Yudiwanti Wahyu² \\ ${ }^{1}$ Agrotechnology, Faculty of Industrial Technology, Gunadarma University \\ ${ }^{2}$ Department of Agronomy and Horticulture, Faculty of Agriculture, Bogor Agricultural University
}

Diterima 22 Desember 2017/Disetujui 29 Januari 2018

\begin{abstract}
Plant breeding activity to assemble hybrid variety in particular fruit size is necessary in order to enhance chili productivity. The objective of this research was to obtain hybrid performance information of genotype diallel cross combination of big and curly chilies. Experimental design used was single factor randomized complete block design (RCBD) by 3 replications. Plant materials were $30 F_{1}$ and 5 commercial varieties. Based on the result, it showed that obtained hybrids had different traits and was significantly not differ to the comparing varieties. Some of potential hybrids were C19 x C2, C5 x C2, C159 $x$ C120, C120 x C5 and C111 x C120.
\end{abstract}

Key words: dunnett, hybrid, pepper, performance, yield

\section{ABSTRAK}

Program pemuliaan tanaman dalam rangka perakitan varietas hibrida dengan ukuran buah tertentu sangat diperlukan untuk upaya peningkatan produktivitas cabai.Tujuan dari penelitian ini adalah memperoleh informasi keragaan hibrida hasil silang dialel genotipe cabai hasil persilangan cabai besar dan cabai keriting. Percobaan disusun dalam rancangan kelompok lengkap teracak (RKLT) faktor tunggal dengan 3 ulangan. Bahan tanaman terdiri atas $30 F_{1}$ dan 5 varietas komersial pembanding. Berdasarkan hasil penelitian diperoleh hibrida dengan karakter yang berbeda nyata dan tidak berbeda nyata dengan varietas pembanding. Beberapa hibrida yang berpotensi untuk dikembangkan lebih lanjut adalah C19x C2, C5 x C2, C159 x C120, C120 x C5, dan C111 x C120.

Kata kunci: cabai, dunnett, hasil, hibrida, keragaan

\section{PENDAHULUAN}

Cabai sebagai komoditas hortikultura bernilai tinggi di Indonesia memiliki beberapa tipe berdasarkan ukuran buahnya, diantaranya adalah cabai rawit, cabai besar, cabai keriting, dan paprika (Berke, 2000). Cabai keriting merupakan salah satu tipe cabai yang memiliki daya simpan lebih lama dan harga jual lebih tinggi dibandingkan dengan cabai besar. Cabai keriting lebih banyak disukai oleh masyarakat di daerah Sumatera karena ciri fisik cabai keriting lebih kering, dan relatif lebih pedas dibandingkan dengan cabai besar. Akan tetapi, cabai keriting memiliki ukuran buah yang lebih ramping, berdaging tipis danumur panen yang lebih lama dibandingkan cabai besar (Greenleaf, 1986) dan memiliki produktivitas yang lebih rendah dari

\footnotetext{
*Penulis untuk korespondensi. e-mail: muhsyukur@ipb.ac.id
}

pada cabai besar (Berke 2000). Berdasarkan data BPS (2011) produktivitas cabai nasional hanya mencapai 6.18 ton ha-1 pada tahun 2011 dan jauh di bawah potensinya, yaitu lebih dari 20 ton ha $^{-1}$ (Syukur et al., 2010a).

Faktor yang menyebabkan rendahnya produktivitas cabai di Indonesia diantaranya adalah belum banyak digunakan varietas hibrida berdaya hasil tinggi. Selanjutnya perbedaan kebiasaan masyarakat dalam hal menanam dan mengonsumsi tipe cabai berdasarkan ukurannya dapat menjadi salah satu faktor rendahnya produktivitas cabai secara nasional. Kegiatan pemuliaan tanaman dalam rangka perakitan varietas unggul baru cabai dengan ukuran buah tertentu sangat diperlukan untuk upaya peningkatan produktivitasnya (Syukur et al. 2010b).Salah satu upaya yang dapat dilakukan adalah dengan merakit varietas hibrida.Tujuan dari penelitian ini adalah memperoleh informasi keragaan hibrida hasil silang dialel genotipe cabai hasil persilangan cabai besar dan cabai keriting. 


\section{BAHAN DAN METODE}

Pelaksanaan penelitian dilakukan pada bulan Oktober 2012 sampai April 2013 di Kebun Percobaan Leuwikopo Departemen Agonomi dan Hortikultura, Fakultas Pertanian Institut Pertanian Bogor. Materi genetik yang digunakan adalah 30 hibrid $\mathrm{F}_{1}$ hasil kombinasi persilangan dialel lengkap dan 5 varietas hibrida komersil, yaitu Gada (PT East West Seed Indonesia), Princess (PT BISI Internasional Tbk), Biola (PT Mulia Bintang Utama), TM999 (PT Seminis Vegetable Seeds Indonesia) dan Tanamo (PT East West Seed Indonesia). Percobaan dilakukan dengan menggunakan rancangan kelompok lengkap teracak (RKLT) satu faktor, yaitu $35 \mathrm{~F}_{1}$ dengan 3 ulangan. Setiap satuan percobaan terdiri atas 20 tanaman dengan 10 tanaman contoh. Kegiatan percobaan diawali dengan kegiatan penyemaian. Pemupukan dilakukan setelah bibit berumur 2 minggu setelah semai menggunakan pupuk NPK15:15:15 (10 $\mathrm{g} \mathrm{L}^{-1}$ air). Penanaman dilakukan setelah bibit cabai berumur 30 hari setelah semai. Bedengan berukuran $1 \mathrm{~m} \times 5 \mathrm{~m}$ dengan jarak antar bedengan $50 \mathrm{~cm}$. Bedengan ditutup dengan mulsa plastik hitam perak dan dibuat lubang tanam dengan jarak $50 \mathrm{~cm}$ x $50 \mathrm{~cm}$. Kegiatan pemeliharaan yang dilakukan yaitu penyiraman pada pagi dan sore hari, pemupukan dilakukan setiap satu minggu sekali menggunakan pupuk NPK15:15:15 (10 $\mathrm{g} \mathrm{L}^{-1}$ air) sebanyak $250 \mathrm{~mL}$ per tanaman, penyemprotan pestisida dilakukan 2 minggu sekali menggunakan fungisida berbahan aktif Mankozeb (2 $\left.\mathrm{g} \mathrm{L}^{-1}\right)$ dan insektisida berbahan aktif Prefonofos ( $\left.2 \mathrm{~mL} \mathrm{~L}^{-1}\right)$. Pemanenan dilakukan saat cabai telah mencapai tingkat kematangan $75 \%$ yang dilakukan setiap minggu selama 8 minggu.

Pengamatan yang akan dilakukan pada percobaan mengacu pada Descriptors for Capsicum (IPGRI, 1995) meliputi:

1. Umur berbunga (hst), jumlah hari setelah tanam sampai $50 \%$ populasi tanaman setiap bedengan berbunga.

2. Umur panen (hst), 50\% tanaman di dalam petak telah mempunyai buah masak pada percabangan pertama.

3. Panjang daun $(\mathrm{cm})$, pengukuran dilakukan terhadap 10 daun dewasa pada percabangan ketiga setelah dikotomus.

4. Lebar daun (cm), pengukuran dilakukan terhadap 10 daun dewasa pada percabangan ketiga setelah dikotomus.

5. Tinggi tanaman $(\mathrm{cm})$, diukur dari pangkal batang sampai titik tumbuh tertinggi, diukur pada panen kedua hingga keempat.

6. Tinggi dikotomus (cm), diukur dari pangkal batang sampai cabang dikotomus, diukur pada panen kedua hingga keempat.

7. Diameter batang $(\mathrm{mm})$, diukur $5 \mathrm{~cm}$ dari permukaan tanah,diukur pada panen kedua hingga keempat.

8. Panjang buah $(\mathrm{cm})$, diambil rata-rata 10 buah setiap ulangan pada panen kedua hingga keempat dan diukur dari pangkal sampai ujung buah.

9. Panjang tangkai buah $(\mathrm{cm})$, diambil rata-rata 10 buah setiap ulangan pada panen kedua hingga keempat dan diukur dari pangkal sampai ujung tangkai buah.

10. Diameter buah $(\mathrm{mm})$, diambil rata-rata 10 buah setiap ulangan pada panen kedua hingga keempat dan diukur mengunakan jangka sorong.

11. Tebal daging buah $(\mathrm{mm})$, diambil rata-rata 10 buah setiap ulangan pada panen kedua hingga keempat. Buah dibelah secara melintang dan diukur tebal daging buahnya menggunakan jangka sorong.

12. Bobot per buah $(\mathrm{g})$, diambil rata-rata 10 buah setiap ulangan pada panen kedua hingga keempat dan diukur menggunakan timbangan analitik.

13. Jumlah buah per tanaman, dihitung dengan menjumlahkan total buah tiap panen selama 8 minggu dan dibagi dengan jumlah tanaman sampel.

14. Bobot buah per tanaman (g), dihitung dengan menjumlahkan bobot buah tiap panen selama 8 minggu dan dibagi dengan jumlah tanaman sampel. Untuk pengamatan peubah nomor 8-12, dilakukan pada 10 buah sampel per ulangan.

\section{Analisis Data}

Perbedaan antar genotipe diuji menggunakan uji $\mathrm{F}$ pada taraf nyata $5 \%$, jika terdapat perbedaan yang nyata dilanjutkan dengan uji lanjut Dunnett taraf 5\% kepada setiap varietas pembanding. Model linier dalam analisis ragam berdasarkan Gomez dan Gomez (2007). Sidik ragam yang digunakan dalam penelitian ini berdasarkan Mattjik dan Sumertajaya (2006). Uji lanjut pada perlakuan yang berbeda nyata dilakukan dengan Uji Dunnett pada taraf 5\% (Gomez dan Gomez 2007).

\section{HASIL DAN PEMBAHASAN}

Hasil analisis ragam evaluasi hibrida untuk karakter yang diamati pada penelitian ini menunjukkan pengaruh yang sangat nyata. Koefisien keragaman antar genotipe yang diuji berada pada kisaran 6.34-19.27\%. Nilai koefisien keragaman di bawah 20\% dianggap sebagai batas keterhandalan model rancangan suatu percobaan (Achsani, 1997). Nilai koefisien keragaman terendah terdapat padakarakter umur panen sedangkan nilai koefisien tertinggi terdapat padakarakter bobot buah per tanaman.

Nilai tengah karakter umur berbunga dan umur panen pada hibrida yang diuji tidak berbeda nyata dengan varietas pembanding TM999, Gada dan Biola (Tabel 1). Kondisi ini menunjukkan bahwa hibrida yang diuji memiliki umur berbunga yang mirip dengan beberapa varietas hibrida yang beredar. Pada karakter umur panen hibrida yang diuji tidak berbeda nyata dengan varietas pembanding TM999, Gada, dan Tanamo yaitu sekitar 70.33-85.67 HST (Tabel 2).

Terdapat dua hibrida yang memiliki ukuran daun paling besar dan berbeda nyata dengan varietas pembanding, yaitu C19×C111 (panjang daun) dan C5×C120 (lebar daun). Karakter tinggi tanaman pada hibrida yang diuji berada pada kisaran 47.60-66.36 cm dan secara umum tidak berbeda nyata dengan varietas TM999 dan Princess. Nilai tengah karakter diameter batang hibrida yang diuji tidak berbeda nyata dengan varietas pembanding dan berada pada kisaran 5.46-7.90 cm, Secara umumnya penampilan dari hibrida 
Istiqlal et al. / Comm. Horticulturae Journal 2(1):14-19

Tabel 1. Kuadrat tengah analisis ragam karakter non buah hibrida cabai

\begin{tabular}{lcccccccc}
\hline \multirow{2}{*}{ Sumber keragaman } & \multirow{2}{*}{$\mathrm{db}$} & \multicolumn{9}{c}{ Kuadrat tengah } \\
\cline { 3 - 9 } & & $\mathrm{UB}$ & $\mathrm{UP}$ & $\mathrm{PD}$ & $\mathrm{LD}$ & $\mathrm{TT}$ & TD & DBT \\
\hline Ulangan & 2 & 41.87 & 56.35 & 0.03 & 0.27 & 423.51 & 27.15 & 7.46 \\
Genotipe & 34 & $20.95^{* *}$ & $67.56^{* *}$ & $1.53^{* *}$ & $0.57^{* *}$ & $151.14^{* *}$ & $36.84^{* *}$ & $1.53^{* *}$ \\
Galat & 68 & 7.95 & 24.45 & 0.38 & 0.31 & 37.02 & 3.27 & 0.77 \\
KK & & 9.72 & 6.34 & 8.09 & 19.75 & 10.67 & 6.43 & 12.96
\end{tabular}

Keterangan : $\quad \mathrm{UB}=$ umur berbunga, $\mathrm{UP}=$ umur panen, $\mathrm{PD}=$ panjang daun, $\mathrm{LD}=$ lebar daun, $\mathrm{TT}=$ tinggi tanaman, $\mathrm{TD}=$ tinggi dikotomus, $\mathrm{DBT}=$ diameter batang, tn, ${ }^{*}, * *=$ berturut-turut hasil uji $\mathrm{F}$ tidak nyata pada taraf $5 \%$, nyata pada taraf $5 \%$ dan nyata pada taraf $1 \%, \mathrm{KK}=$ koefisien keragaman

Tabel 2. Kuadrat tengah analisis ragam karakter buah hibrida cabai

\begin{tabular}{lcccccccc}
\hline \multirow{2}{*}{ Sumber keragaman } & \multirow{2}{*}{$\mathrm{db}$} & \multicolumn{1}{c}{ Kuadrat tengah } \\
\cline { 3 - 9 } & 2 & 2.02 & 0.60 & 1.85 & 0.84 & 0.01 & 29.98 & 1377.71 \\
Ulangan & 24 & $12.86^{* *}$ & $0.53^{* *}$ & $43.36^{* *}$ & $22.65^{* *}$ & $0.26^{* *}$ & $2157.57^{* *}$ & $9314.97^{* *}$ \\
Genotipe & 68 & 1.42 & 0.08 & 0.60 & 0.79 & 0.02 & 71.70 & 2128.23 \\
Galat & & 8.15 & 8.11 & 6.44 & 12.68 & 8.19 & 11.62 & 19.27 \\
KK & & & & & & & &
\end{tabular}

Keterangan: $\quad \mathrm{PB}=$ panjang buah, $\mathrm{PTB}=$ panjang tangkai buah, $\mathrm{DB}=$ diameter buah, $\mathrm{TDB}=$ tebal daging buah, $\mathrm{BB}=$ bobot per buah, $\mathrm{JBT}=$ jumlah buah per tanaman, $\mathrm{BBT}=$ bobot buah per tanaman, $\mathrm{tn}, *, * *=$ berturut-turut hasil uji $\mathrm{F}$ tidak nyata pada taraf $5 \%$, nyata pada taraf $5 \%$ dan nyata pada taraf $1 \%, \mathrm{KK}=$ koefisien keragaman

yang diuji berkaitan dengan karakter non buah tidak berbeda dengan varietas pembanding (Tabel 4).

Pada karakter panjang buah dan panjang tangkai buah pada hibrida C19 x C120, C111 x C120, C120 x C2, C120 x C19, C120 x C111, C120 x C159 dan C159 x C120 memiliki nilai tengah tergolong tinggi dan berbeda nyata dengan umumnya varietas pembanding yang digunakan. Pada karakter diameter buah, tebal daging buah dan bobot per buah hibrida C19 x C5 adalah hibrida berbeda nyata dengan kelima varietas pembanding dan menujukkan nilai tengah yang lebih tinggi, yaitu $21.14 \mathrm{~mm}, 2.24 \mathrm{~mm}$ dan $12.71 \mathrm{~g}$ buah $^{-1}$. Walaupun demikian hibrida C19 x C5 memiliki jumlah buah per tanaman paling sedikit, yaitu 32 buah per tamanan dan berbeda nyata dengan varietas pembanding TM999, Tanamo dan Princess. Karakter jumlah buah per tamanan memiliki kisaran antara 32-141 buah per tanaman, hibrida C159 x C10 dan C111 x C120 adalah hibrida yang memiliki jumlah buah per tanaman paling banyak daripada hibrida lainya dan kelima varietas pembanding, yaitu 141 dan 137 buah per tanaman (Tabel 4).

Potensi poduktivitas cabai pada hibrida yang diuji berada pada kisaran 143.89 hingga 349.66 g tanaman $^{-1}$. Nilai tengah tertinggi untuk bobot buah per tanaman terdapat pada hibrida C19 x C2, yaitu 349.56 g tanaman $^{-1}$, nilai ini berbeda nyata dengan varietas pembanding kecuali varietas Tanamo. Sementara itu, potensi poduktivitas cabai pada varietas pembandiung yang diuji berada pada kisaran 171.23 hingga 250.62 g tanaman $^{-1}$. Tanaman cabai dengan bobot buah per tanaman minimal $500 \mathrm{~g} \mathrm{tanaman}^{-1}$ akan mencapai potensi hingga 12 ton $\mathrm{ha}^{-1}$. Hibrida yang diuji memiliki potensi hasil lebih baik dari pada varietas pembanding yaitu sekitar 8 ton ha $^{-1}$ dengan kondisi lahan yang marjinal. Bila dikaitkan dengan potensi awal varietas pembanding (misalnya: varietas Tanamo) yaitu dari 32 ton ha $^{-1}$ menjadi 6 ton ha $^{-1}$, dengan demikian bila hibrida yang diuji ditanaman pada lahan optimal akan memiliki potensi hasil mencapai 40 ton $\mathrm{ha}^{-1}$.

Kondisi hibrida yang dihasilkan umumnya memiliki penampilan berkaitan dengan karakter non buah yang tidak berbeda dengan varietas pembanding, akan tetapi memiliki perbedaan yang signifikan berkaitan dengan penampilan karakter buah. Hal ini menunjukkan bahwa, hibrida yang diuji lebih baik dari pada varietas pembanding berkaitan dengan karakter buah atau daya hasil.

\section{KESIMPULAN}

Hibrida yang diuji umumnya memiliki karakter non buah yang tidak berbeda nyata varietas pembanding. Hibrida yang diuji umumnya memiliki karakter buah yang berbeda nyata varietas pembanding. Hibrida yang diuji memiliki potensi hasil sebesar sekitar 8 ton ha $^{-1}$ pada kondisi lahan yang marjinal. Beberapa hibrida yang berpotensi untuk dikembangkan lebih lanjut adalah C19 x C2, C5 x C2, C159 x C120, C120 x C5, dan C111 x C120. 
Tabel 3. Rata-rata karakter non buah pada hibrida cabai

\begin{tabular}{|c|c|c|c|c|c|c|c|c|c|}
\hline \multicolumn{3}{|c|}{ Hibrida } & \multirow{2}{*}{$\begin{array}{c}\text { UB (HST) } \\
27.33 \mathrm{e}\end{array}$} & \multirow{2}{*}{$\begin{array}{c}\text { UP (HST) } \\
72.00 \mathrm{ce}\end{array}$} & \multirow{2}{*}{$\frac{\mathrm{PD}(\mathrm{cm})}{7.96}$} & \multirow{2}{*}{$\begin{array}{c}\mathrm{LB}(\mathrm{cm}) \\
3.08\end{array}$} & \multirow{2}{*}{$\frac{\mathrm{TT}(\mathrm{cm})}{48.35 \mathrm{~d}}$} & \multirow{2}{*}{$\begin{array}{l}\mathrm{TD}(\mathrm{cm}) \\
25.23 \mathrm{ab}\end{array}$} & \multirow{2}{*}{$\frac{\mathrm{DB}(\mathrm{mm})}{6.23}$} \\
\hline$\overline{\mathrm{C} 2}$ & $x$ & $\mathrm{C} 5$ & & & & & & & \\
\hline $\mathrm{C} 2$ & $\times$ & C19 & 31.33 & 74.00ce & $6.71 \mathrm{~d}$ & 2.58 & $49.34 d$ & $30.28 b$ & $5.50 \mathrm{~d}$ \\
\hline $\mathrm{C} 2$ & $\times$ & C111 & $26.00 \mathrm{e}$ & $70.67 \mathrm{ce}$ & 7.19 & 2.43 & $56.89 \mathrm{bd}$ & $30.53 b$ & 6.07 \\
\hline $\mathrm{C} 2$ & $\times$ & $\mathrm{C} 120$ & $27.33 \mathrm{e}$ & $75.00 \mathrm{c}$ & 7.25 & 2.54 & $49.34 d$ & $29.25 b$ & 6.21 \\
\hline $\mathrm{C} 2$ & $\times$ & C159 & 31.67 & 78 & 7.86 & 2.75 & $61.20 \mathrm{~b}$ & $29.59 b$ & 6.52 \\
\hline $\mathrm{C} 5$ & $x$ & $\mathrm{C} 2$ & $26.33 \mathrm{e}$ & $71.67 \mathrm{ce}$ & $8.83 \mathrm{ab}$ & 3.3 & $48.85 \mathrm{~d}$ & $24.80 \mathrm{ab}$ & 7.06 \\
\hline $\mathrm{C} 5$ & $\times$ & C19 & 31.33 & $76.00 \mathrm{c}$ & 7.58 & 3.08 & $49.67 d$ & $27.13 b$ & 6.7 \\
\hline $\mathrm{C} 5$ & $x$ & C111 & 31.33 & 78.33 & $9.01 \mathrm{abe}$ & 3.35 & $57.59 \mathrm{bcd}$ & $22.08 \mathrm{ae}$ & 7.79 \\
\hline $\mathrm{C} 5$ & $\times$ & $\mathrm{C} 120$ & 30.33 & 82.33 & 7.62 & 4.47abcde & $60.79 b$ & $25.21 \mathrm{ab}$ & 7.62 \\
\hline $\mathrm{C} 5$ & $\times$ & C159 & $27.67 \mathrm{e}$ & 77 & 7.27 & 2.72 & $52.54 d$ & $29.19 b$ & 6.58 \\
\hline C19 & $\times$ & $\mathrm{C} 2$ & $32.67 \mathrm{~d}$ & 81.33 & $8.58 \mathrm{ab}$ & 3.18 & $51.63 d$ & $28.05 \mathrm{~b}$ & $5.85^{\mathrm{d}}$ \\
\hline C19 & $x$ & $\mathrm{C} 5$ & 28.67 & $71.33 \mathrm{ce}$ & 7.82 & 3.03 & $48.34 d$ & $25.86 \mathrm{ab}$ & 6.7 \\
\hline C19 & $\times$ & C111 & 28.67 & $76.00 \mathrm{c}$ & $9.05 \mathrm{abe}$ & 3.36 & $56.62 \mathrm{bd}$ & $31.38 \mathrm{bd}$ & 6.22 \\
\hline C19 & $\times$ & $\mathrm{C} 120$ & 31.33 & $75.00 \mathrm{c}$ & 8.06 & 3 & $64.13 b$ & $31.42 \mathrm{bd}$ & 6.52 \\
\hline C19 & $\times$ & C159 & $32.67 \mathrm{~d}$ & 71.33ce & 7.94 & 2.94 & $53.01 d$ & $30.89 b$ & 6.29 \\
\hline C111 & $x$ & $\mathrm{C} 2$ & $24.67 \mathrm{e}$ & $70.33 \mathrm{ce}$ & 7.34 & 2.5 & $56.00 \mathrm{bd}$ & $31.55 \mathrm{bd}$ & 5.97 \\
\hline C111 & $x$ & $\mathrm{C} 5$ & 28.67 & $75.00 \mathrm{c}$ & 7.46 & 2.82 & $48.60 \mathrm{~cd}$ & $22.40 \mathrm{ae}$ & 6.49 \\
\hline C111 & $\times$ & C19 & 30.33 & 77 & 7.43 & 2.8 & $47.60 \mathrm{~cd}$ & $22.42 \mathrm{ae}$ & 6.76 \\
\hline C111 & $x$ & $\mathrm{C} 120$ & $26.33 \mathrm{e}$ & 82 & $6.32 \mathrm{~cd}$ & 2.34 & $64.51 b$ & $27.77 b$ & 7.49 \\
\hline C111 & $\times$ & C159 & 31.67 & 85.67 & 7.65 & 2.74 & $57.79 b d$ & $31.39 \mathrm{bd}$ & 6.85 \\
\hline $\mathrm{C} 120$ & $x$ & $\mathrm{C} 2$ & $27.33 \mathrm{e}$ & 82.33 & 7.44 & 2.54 & $63.95 b$ & $28.17 b$ & 7.79 \\
\hline $\mathrm{C} 120$ & $x$ & $\mathrm{C} 5$ & $26.33 \mathrm{e}$ & 80 & 8.05 & 3.22 & $56.74 \mathrm{bd}$ & $27.08 b$ & 8.29 \\
\hline C120 & $\times$ & C19 & 30.33 & 77 & 7.48 & 2.75 & $64.69 b$ & $31.49 \mathrm{bd}$ & 6.23 \\
\hline $\mathrm{C} 120$ & $x$ & C111 & $27.33 \mathrm{e}$ & 78 & $6.70 \mathrm{~d}$ & 2.2 & $60.73 b$ & $33.66 \mathrm{bd}$ & 6.04 \\
\hline C120 & $\times$ & C159 & 34.00abd & 83 & $6.63 d$ & 2.34 & $66.36 b$ & $32.76 \mathrm{bd}$ & 6.79 \\
\hline C159 & $\times$ & $\mathrm{C} 2$ & 30 & 82 & 7.61 & 2.73 & $65.28 b$ & $29.69 b$ & 7.17 \\
\hline C159 & $x$ & $\mathrm{C} 5$ & 29 & 78 & 9.00abe & 3.38 & $58.99 b$ & $25.26 \mathrm{ab}$ & 7.9 \\
\hline C159 & $\times$ & C19 & 30 & 83 & 8.39 & 3.22 & $57.95 b d$ & $29.11 b$ & $5.46 \mathrm{~d}$ \\
\hline C159 & $x$ & C111 & $26.33 \mathrm{e}$ & 77 & $6.66 \mathrm{~d}$ & 2.47 & $61.85 b$ & $33.04 \mathrm{bd}$ & 6.73 \\
\hline C159 & $\times$ & $\mathrm{C} 120$ & $27.33 \mathrm{e}$ & 80.67 & 7.34 & 2.5 & $63.63 \mathrm{bc}$ & $22.97 \mathrm{ae}$ & 7.22 \\
\hline TM99 & 73) & & 26 & 75 & 6.95 & 2.46 & 59 & 30.92 & 6.89 \\
\hline Gada & & & 26 & 74 & 6.85 & 2.52 & 39.83 & 19.46 & 6.59 \\
\hline Biola & & & 29 & 88.67 & 8.03 & 2.99 & 60.27 & 29.17 & 7.37 \\
\hline Tanam & C161 & & 25 & 82.33 & 8.36 & 2.4 & 74.13 & 26.49 & 8.12 \\
\hline Prince & $\mathrm{C} 282$ & & 35 & 86.67 & 7.39 & 2.67 & 59.78 & 29.33 & 6.31 \\
\hline
\end{tabular}

Keterangan : angka yang diikuti oleh huruf yang sama pada kolom yang sama menunjukan tidak berbeda nyata pada uji Dunnett's $5 \%$.

\section{UCAPAN TERIMA KASIH}

Terima kasih disampaikan kepada DIKTI Kemendikbud yang telah membiayai penelitian ini melalui Hibah PEKERTI Tahun 2012 dan Kemenristek yang telah membiayai penelitian ini melalui Hibah Insentif Riset SINas Tahun 2013.

\section{DAFTAR PUSTAKA}

Achsani, N.A. 1997. Metode pendugaan koefisien keragaman dengan penduga ciutan (shrinkage estimator). Tesis. Sekolah Pascasarjana, Institut Pertanian Bogor. Bogor. 
Tabel 4. Rata-rata karakter buah pada hibrida cabai

\begin{tabular}{|c|c|c|c|c|c|c|c|c|c|}
\hline \multicolumn{3}{|c|}{ Hibrida } & \multirow{2}{*}{$\frac{\mathrm{PB}(\mathrm{cm})}{13.52}$} & \multirow{2}{*}{$\frac{\text { PTB }(\mathrm{cm})}{3.82 \mathrm{bde}}$} & \multirow{2}{*}{$\frac{\mathrm{DB}(\mathrm{mm})}{18.97 \mathrm{abcde}}$} & \multirow{2}{*}{$\frac{\mathrm{TBD}(\mathrm{mm})}{1.85 \mathrm{ae}}$} & \multirow{2}{*}{$\frac{\mathrm{BB}(\mathrm{g})}{11.10 \mathrm{abcde}}$} & \multirow{2}{*}{$\begin{array}{c}\text { JBT } \\
46.26 \text { ade }\end{array}$} & \multirow{2}{*}{$\begin{array}{c}\text { BBT }(\mathrm{g}) \\
241.71\end{array}$} \\
\hline $\mathrm{C} 2$ & $x$ & $\mathrm{C} 5$ & & & & & & & \\
\hline $\mathrm{C} 2$ & $x$ & C19 & $15.36 \mathrm{ce}$ & 3.57 & 15.76abcde & $1.98 \mathrm{ae}$ & 11.54abcde & 44.63ade & 259.57 \\
\hline $\mathrm{C} 2$ & $x$ & $\mathrm{C} 111$ & 14.4 & 3.23 & $10.69 \mathrm{ab}$ & $1.79 \mathrm{ae}$ & $6.55 \mathrm{ae}$ & $61.25 \mathrm{ad}$ & 188.56 \\
\hline $\mathrm{C} 2$ & $x$ & $\mathrm{C} 120$ & 16.62ace & $3.83 \mathrm{bde}$ & 13.42ade & $1.89 \mathrm{ae}$ & 8.03ade & 45.83ade & 253.56 \\
\hline $\mathrm{C} 2$ & $x$ & $\mathrm{C} 159$ & 14.02 & 3.49 & 11.09abe & $1.41 \mathrm{bd}$ & $5.52 \mathrm{bce}$ & $87.70 \mathrm{bc}$ & 242.21 \\
\hline C5 & $x$ & $\mathrm{C} 2$ & 14.22 & 3.89abde & 20.25abcde & $1.92 \mathrm{ae}$ & 12.65abcde & $51.59 \mathrm{de}$ & 340.96abce \\
\hline $\mathrm{C} 5$ & $x$ & C19 & 13.04 & $3.81 \mathrm{bde}$ & 18.02abcde & 2.09ace & 11.67abcde & 42.54ade & $294.04 \mathrm{e}$ \\
\hline C5 & $x$ & $\mathrm{C} 111$ & $12.79 d$ & 3.89abde & 12.97ade & $1.69 \mathrm{ae}$ & $6.65 \mathrm{ae}$ & $87.35 \mathrm{bc}$ & 310.71ace \\
\hline $\mathrm{C} 5$ & $x$ & $\mathrm{C} 120$ & 16.79ace & 4.36abcde & $14.05 \mathrm{acde}$ & $1.74 \mathrm{ae}$ & 8.42ade & $61.38 \mathrm{ad}$ & 268.41 \\
\hline $\mathrm{C} 5$ & $x$ & $\mathrm{C} 159$ & $14.75 \mathrm{e}$ & 3.87abde & 11.90ade & $1.61 \mathrm{e}$ & $6.98 \mathrm{ae}$ & $64.48 \mathrm{ad}$ & 145.67 \\
\hline C19 & $\times$ & $\mathrm{C} 2$ & 13.16 & 3.14 & $12.40 \mathrm{ade}$ & $1.55 \mathrm{bde}$ & $7.48 \mathrm{ae}$ & $77.13 \mathrm{abc}$ & 349.56abce \\
\hline C19 & $x$ & $\mathrm{C} 5$ & 13.88 & 3.71bde & 21.14abcde & 2.24ace & 12.71abcde & 32.74ade & 224.12 \\
\hline C19 & $\times$ & C111 & $12.42 \mathrm{~d}$ & 2.9 & 12.03ade & $1.61 \mathrm{e}$ & 5.98abe & 69.27abcd & 266.8 \\
\hline C19 & $x$ & $\mathrm{C} 120$ & 17.59abce & 3.97abcde & 14.31acde & $1.60 \mathrm{e}$ & 10.48 acde & 54.79ade & 271.73 \\
\hline C19 & $x$ & $\mathrm{C} 159$ & 13.91 & 3.5 & 11.44ade & $1.63 \mathrm{e}$ & 5.94abe & 43.95ade & 177.95 \\
\hline C111 & $\times$ & $\mathrm{C} 2$ & 14.36 & 3.4 & $11.29 \mathrm{ae}$ & $1.94 \mathrm{ae}$ & $6.43 \mathrm{ae}$ & $62.46 \mathrm{ad}$ & $219.52 \mathrm{c}$ \\
\hline C111 & $x$ & $\mathrm{C} 5$ & $11.90 \mathrm{~d}$ & 3.24 & 12.43ade & $1.69 \mathrm{ae}$ & $6.65 \mathrm{ae}$ & $99.53 \mathrm{bce}$ & 278.88 \\
\hline C111 & $x$ & C19 & $12.72 d$ & 3.33 & 12.68ade & $1.70 \mathrm{ae}$ & $6.75 \mathrm{ae}$ & $68.81 \mathrm{abcd}$ & 205.93 \\
\hline C111 & $x$ & $\mathrm{C} 120$ & 18.34abce & $3.67 \mathrm{e}$ & $7.18 \mathrm{bcd}$ & $1.32 \mathrm{bcd}$ & $4.11 b$ & 137.42abcde & $308.61 \mathrm{ae}$ \\
\hline C111 & $x$ & $\mathrm{C} 159$ & $12.81 \mathrm{~d}$ & 2.89 & $6.82 \mathrm{bcd}$ & $1.05 \mathrm{bcd}$ & $2.86 \mathrm{bcd}$ & 70.26abcd & 157.51 \\
\hline $\mathrm{C} 120$ & $x$ & $\mathrm{C} 2$ & 18.29abce & 3.98abcde & 11.79ade & $1.69 \mathrm{ae}$ & 7.01ae & $90.35 b c$ & 233.55 \\
\hline $\mathrm{C} 120$ & $\times$ & $\mathrm{C} 5$ & 14.24 & 4.19abcde & 17.13abcde & 2.09ace & 9.89ade & $62.34 \mathrm{ad}$ & 313.01ace \\
\hline $\mathrm{C} 120$ & $\times$ & C19 & 17.90abce & 4.08abcde & 12.79 ade & $1.65 \mathrm{ae}$ & $7.85 \mathrm{ae}$ & 48.92ade & 229.94 \\
\hline $\mathrm{C} 120$ & $x$ & $\mathrm{C} 111$ & 18.06abce & 3.87abde & $7.01 \mathrm{bcd}$ & $1.23 \mathrm{bcd}$ & $4.11 b c$ & $102.68 \mathrm{bce}$ & 240.05 \\
\hline $\mathrm{C} 120$ & $x$ & C159 & 17.64abce & 4.04abcde & $7.88 \mathrm{bc}$ & $1.36 \mathrm{bd}$ & $4.37 b c$ & $95.32 b c$ & 226.46 \\
\hline C159 & $x$ & $\mathrm{C} 2$ & 13.96 & 3.23 & 10.18be & $1.39 \mathrm{bd}$ & $5.43 \mathrm{bce}$ & $92.53 b c$ & 214.8 \\
\hline C159 & $x$ & $\mathrm{C} 5$ & 13.41 & 3.86abde & 11.66ade & $1.44 \mathrm{bd}$ & 6.29abe & $90.74 b c$ & 256.9 \\
\hline C159 & $\times$ & C19 & 14.12 & 3.49 & 11.15abe & $1.75 \mathrm{ae}$ & 5.69abe & 46.72ade & 143.89 \\
\hline C159 & $x$ & $\mathrm{C} 111$ & $12.23 \mathrm{~d}$ & 3.15 & $7.21 \mathrm{bcd}$ & $1.14 \mathrm{bcd}$ & $3.18 \mathrm{bcd}$ & $99.91 \mathrm{bcde}$ & 175.61 \\
\hline C159 & $\times$ & $\mathrm{C} 120$ & 17.69abce & 4.06abcde & $8.30 \mathrm{bc}$ & $1.35 \mathrm{bd}$ & $4.40 \mathrm{bc}$ & 141.92abce & 339.63 \\
\hline \multicolumn{3}{|c|}{ TM999 (C73) } & 12.77 & 3.12 & & 1.3 & & 101.6 & 187.05 \\
\hline \multicolumn{3}{|c|}{ Gada (C74) } & 14.06 & 2.94 & 13.23 & 1.91 & & & 203.88 \\
\hline \multicolumn{3}{|c|}{ Biola (C77) } & 12.1 & 3.23 & 12.05 & 1.67 & & & 182.78 \\
\hline \multicolumn{3}{|c|}{ Tanamo (C161) } & 15.92 & 2.97 & & 1.93 & & & 250.62 \\
\hline \multicolumn{3}{|c|}{ Princess (C282) } & 11.55 & 2.84 & & 1.16 & & & 171.23 \\
\hline
\end{tabular}

Keterangan : angka yang diikuti oleh huruf yang sama pada kolom yang sama menunjukan tidak berbeda nyata pada uji Dunnett's $5 \%$.

Berke, T.G. 2000. Hybrid Seed Production in Capsicum. Editor: Basra. 2000. Hybrid Seed Production In Vegetables: Rationale and Methods In Selected Crops. New York (US): Haworth Press Inc.

[BPS] Badan Pusat Statistik. 2011. Luas panen, produksi dan produktivitas cabai, 2009-2011. http://www.bps. go.id/. [10 September 2012].

Gomez, K.A., A.A. Gomez. 2007. Prosedur statistika untuk penelitian pertanian. Penerjemah Syamsudin E dan Baharsjah JS. Statistical Procedurs for Agriculture Research. UI Press. Jakarta. 
Greenleaf, W.H. 1986. Pepper breeding, p 67-127.Editor: Basset MJ. Breeding Vegetable Crops. Westport (IR): AVI Publishing.

[IPGRI] International Plant Genetic Resources Institute. 1995. Descriptors for Capsicum (Capsicum spp.). Italia. $51 \mathrm{p}$.

Mattjik, A.A., I.M. Sumertajaya. 2006. Perancangan Percobaan dengan Aplikasi SAS dan Minitab. IPB Press. Bogor.
Syukur, M., S. Sujiprihati, R. Yunianti., D.A. Kusumah. 2010a. Yield evaluation of pepper hybrids and their adaption at four location in two years. J. Agron Indonesia. 38(1):43-51.

Syukur, M., S. Sujiprihati, R. Yunianti, Undang. 2010 b. Diallel analysis using hayman method to study genetic parameters of yield components in pepper (Capsicum annuum L.). Hayati J Biosci. 17(4):183-188. 